\title{
Grid Powered Fast Charge Electric - Vehicle Stations
}

\author{
Dr. S. Devaneyan ${ }^{1}$ \\ Dean - Research \& Development, Ansal University, Gurugram, Haryana, India ${ }^{1}$
}

\begin{abstract}
Mass creation of aggregate electric vehicles equipped for voyaging longer separations results in a requirement for electric administration stations that can fulfil the necessities for a lot of intensity gave in a period term like that of filling a vehicle with oil-based fuel. These vehicles would manoeuvre into the station, and need a lot of intensity conveyed over a brief timeframe for the quick energizing of batteries which fill in as their "fuel tank." This paper examines the impact of quick charging electric vehicles on a current service organization circulation framework at several determined locales. This paper will cover control stream, short out, and security learns at these locales utilizing utility-review programming bundles. What's more, the investigation of re-enactments of a reviving station where up to eight quickly battery-powered vehicles please line without a moment's delay will be displayed.
\end{abstract}

Keywords: Distribution Framework, Electric Vehicle, Fast Charging, Guard, Voltage Drop

\section{INTRODUCTION}

In India about millions of barrels of oil are used each day and 2/3 of these are refined into automobile fuel. There is a clear economic and political incentive for the development of electric vehicles, considering the volatile price of oil and gasoline. Automobile emissions are also known to add a significant amount of contaminants to the air each year. Pollution has long been a concern for the urban areas across the nation. While this originally was of concern only to large metropolitan areas, such as New Delhi and Mumbai, today almost every city has air pollution concerns. Some agencies have taken upon themselves the stewardship of this difficulty.

The ill consequences of pollution have given birth to agencies, such as the Indian Pollution control Board (IPCB), which governs emissions in India. IPCB has issued several regulations with the goal of reducing emissions. This has forced conventional and new auto manufacturers to invest in technologies that will lead to the production of Zero Emission Vehicles (ZEVs) and the near zero emission vehicles (i.e. hybrid vehicles). The rapid development and major accomplishments for the production of advanced batteries have also resulted in significant interest toward the development of total electric vehicles. Battery-powered electric vehicles (BEVs) produce no direct emissions and current energy prices are in favour of them.

Electric motors are more efficient than internal combustion engines and can take advantage of energy-saving techniques, such as regenerative braking, which recovers some of the energy that would otherwise be lost as heat and friction. These new battery-powered electric vehicles should be equipped with advanced commercial-grade batteries that will be able to withstand at least 10,000 rapid charges, charging in $10 \mathrm{~min}$ or less, without any issues or performance degradation. Mass production of total electric vehicles capable of travelling longer distances results in a need for electric service stations that can satisfy the requirements for a significant amount of power provided in a time duration similar to that of filling a car with oil-based fuel. These vehicles could pull into the station and need a large amount of power delivered over a short period of time for the rapid recharging of batteries which serve as their "fuel tank".

Expectedly, the "fast charge stations" would be located primarily in residential and light commercial locations. The existing electric infrastructure may not be adequately designed to satisfy the surge in power demand for the necessary electric service stations in these areas. Under the existing conditions, this type of load could create problems, such as voltage sags, flicker, and harmonics which may cause public annoyance and/or ab-normal operations or physical damage to the electrical equipment in the area. This paper presents an investigation regarding the effect of fast-charging electric vehicles on an existing electric utility distribution system at four specific sites. The report will cover powerflow, short-circuit, and protection studies of the four different locations using utility-grade software packages. In addition, the analysis of simulations of a recharging station where up to eight rapidly rechargeable vehicles come online at once will be presented. 


\title{
International Advanced Research Journal in Science, Engineering and Technology
}

\author{
Vol. 5, Issue 12, December 2018
}

\section{EXISTING TECHNOLOGIES}

It is important to review the current technologies, specifically energy-storage devices (batteries) for the development of an electric vehicle. Knowing trends in vehicle energy storage will allow for better prediction and modelling of the system load under vehicle-charging conditions.

\section{A. Batteries}

The main battery selection criteria are: type, size (energy density), weight, cost, life cycle, maturity, efficiency, availability, and dependability. There are a variety of batteries being researched. Examples include: metal-air battery, sodium sulphur (NAS) battery, flow battery, Li-ion battery, and lead-acid battery. At this time, the lithium-ion titanate batteries appear to be the best rechargeable batteries for vehicle implementation. These batteries are lightweight and powerful when compared to other.
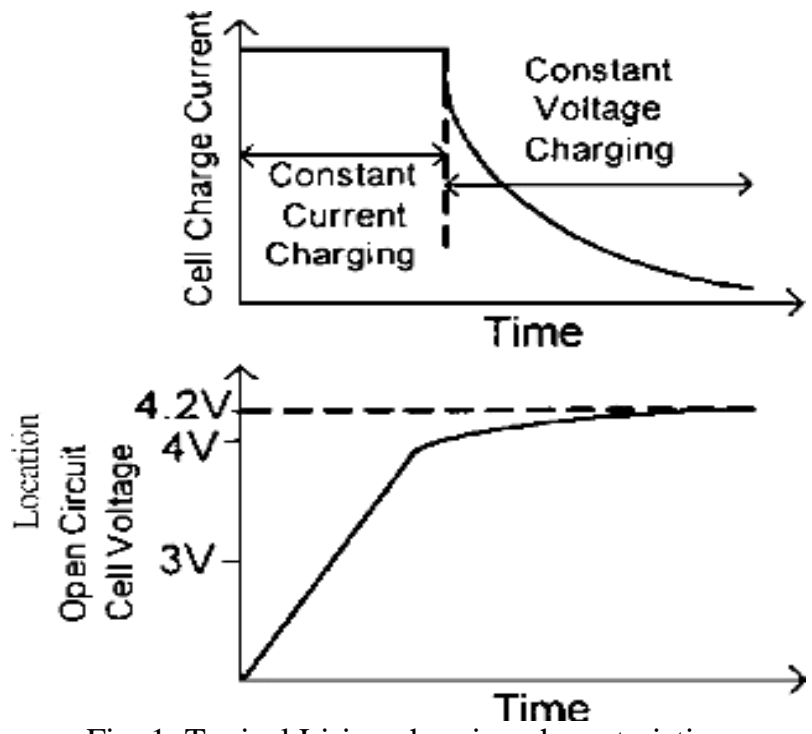

Fig. 1. Typical Li-ion charging characteristics

Table I: System Equivalents For The Four Tested Locations (Sequence Impedances In Ohms)

\begin{tabular}{|l|l|c|c|}
\hline & Positive & Negative & Zero \\
\hline A & $12.25+j 23.90$ & $12.25+j 23.90$ & $18.53+j 74.41$ \\
\hline B & $6.11-j 11.51$ & $6.11-j 11.51$ & $7.89-j 24.42$ \\
\hline C & $.86+j 3.65$ & $.86+j 3.65$ & $2.10+j 9.50$ \\
\hline D & $11.52+j 18.24$ & $11.52+j 18.24$ & $9.34+j 27.05$ \\
\hline
\end{tabular}

Battery materials, and capable of rapid recharging in 10 min or less. Furthermore, due to their unique construction, the titanate batteries do not have stability and plating issues and have a lifespan that is nearly 10 times greater than other Liion battery constructions. With the right charger, these batteries are capable of recharging in approximately 10 min to $95 \%$ of full capacity.

\section{B. Charging Techniques}

1) Power Rectification: An ac-dc conversion unit that is ideal for fast charging would be required to meet the demands of fast-charging cars. Some current ac-dc rectifiers offer clean power at $99 \%$ power factor and less than $3 \%$ total harmonic distortion. These rectifiers would be based on power electronics capable of transforming high power ac to high power dc. Current market rectifiers, approximately six feet wide by six feet tall and three feet deep, would come to resemble the fuel pumps found at gasoline stations today.

2) Li-Ion Charging Traits: The charging characteristics of a lithium-ion titanate battery used for simulations will follow the constant current-constant voltage charging $(\mathrm{CC}-\mathrm{CV})$ method common to lithium-ion batteries as described in and shown in Fig. 1. 
International Advanced Research Journal in Science, Engineering and Technology

Vol. 5, Issue 12, December 2018

\section{MODELLING AND ANALYSIS}

1) Power-Flow Study: Using respective power-flow software and actual utility system equivalents, power-flow simulations were performed. A 2-MW load at .99 power factor was used to represent simultaneous charging of eight EVs. Note that even though an instantaneous 2-MW load may not occur that often, this paper assumes a worst-case scenario for the simultaneous arrival of all eight cars. Four different locations were considered in order to determine the 2-MW loading effect. Table I displays the system equivalents for these locations.

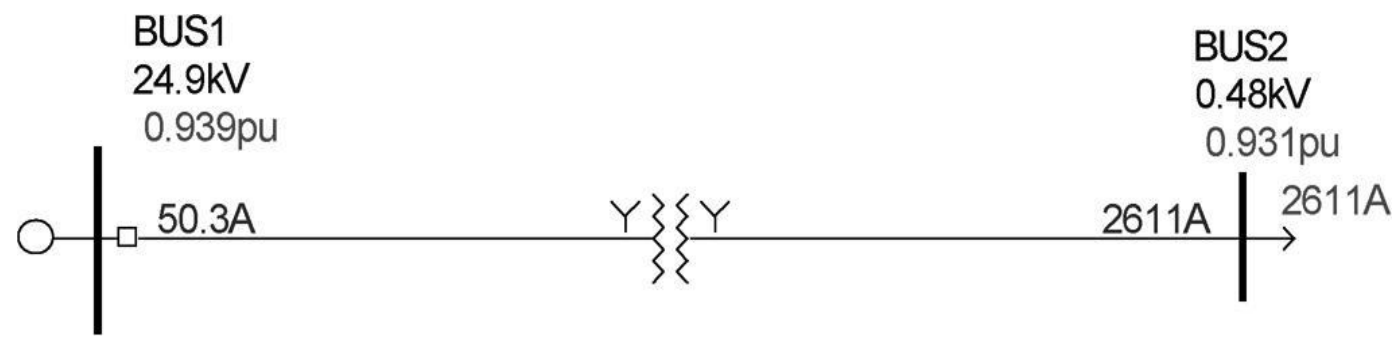

Fig. 2. Power-flow simulation of the 2-MW load at location "A."

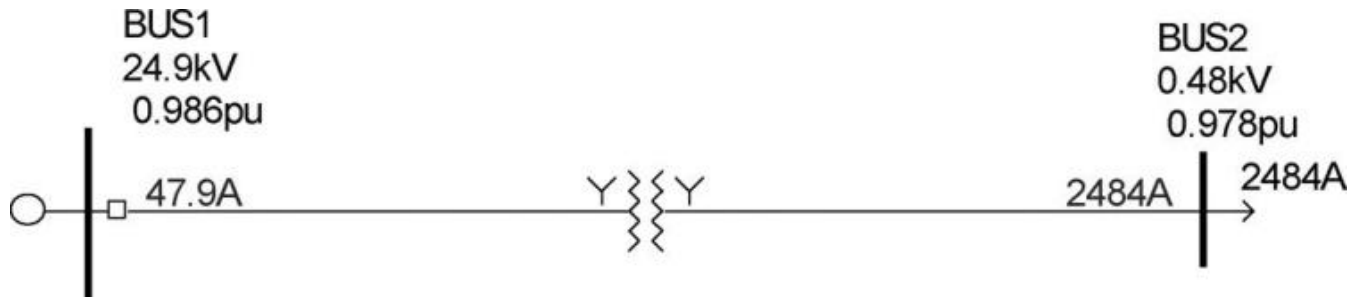

Fig. 3. Power-flow simulation of a 2-MW load at location "B."

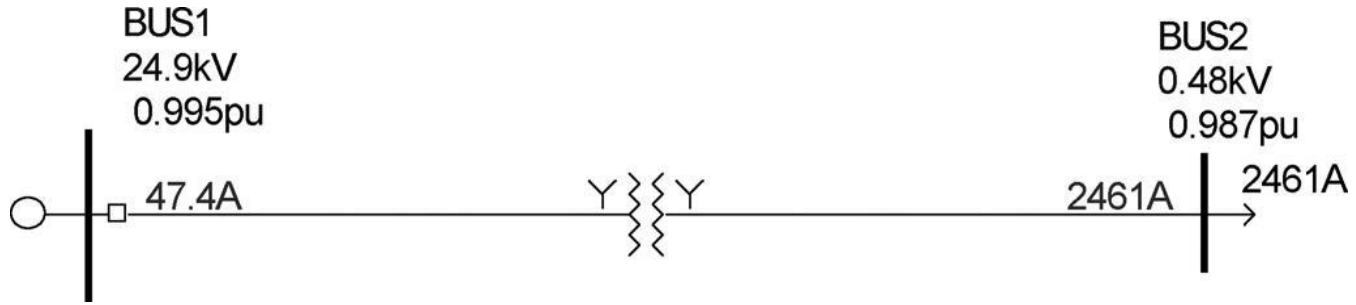

Fig. 4. Power-flow simulation of a 2-MW load at location "C."

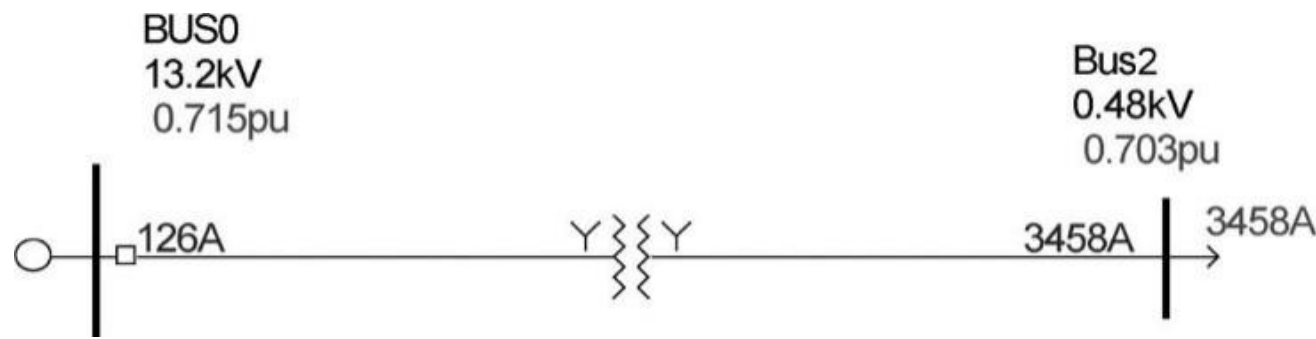

Fig. 5.Power-flow simulation of a 2-MW load at location "D."

Note that instead of a voltage drop calculation, the power-flow program is used here because constant load simulation was desired. The simulated recharge station feeders are specified to have a line-line voltage of $480 \mathrm{~V}$. To achieve this secondary voltage, a dedicated standard distribution trans-former rated at 2.5 MVA, $24.9 \mathrm{kV}$ (GRD Y) to $480 \mathrm{~V}$ (GRD Y) was used for simulation purposes. For location D, which is rated at $13.2 \mathrm{kV}$, a dedicated $2.5 \mathrm{MVA}, 13.2 \mathrm{kV}$, (GRD Y) to $480 \mathrm{~V}$ (GRD Y) was used. As shown in Figs. 2-5, the simulation results for these four locations indicate a load current of 47.9 A and 47.4 A on the primary side of the distribution transformer for locations B and C, respectively. Figs. 2 and 5 show that locations A and D have undesirable voltage drops and are currently not ideal for simultaneous charging of eight car stations (2-MW loads). Note that we are assuming no compensation techniques, such as an onsite storage facility or ramp up, and interlock strategies are used.

Table II provides the results of various power-flow simulations for determining the maximum number of vehicles that can simultaneously be charged without violating the utility standard. 


\section{International Advanced Research Journal in Science, Engineering and Technology}

Vol. 5, Issue 12, December 2018

Table II Maximum Cars and Load Per Location

\begin{tabular}{|c|c|c|}
\hline Location & Maximum number of cars & Load \\
\hline $\mathrm{A}$ & 3 & $750 \mathrm{~kW}$ \\
\hline $\mathrm{B}$ & 8 & $2 \mathrm{MW}$ \\
\hline $\mathrm{C}$ & 8 & $2 \mathrm{MW}$ \\
\hline $\mathrm{D}$ & 1 & $250 \mathrm{~kW}$ \\
\hline
\end{tabular}

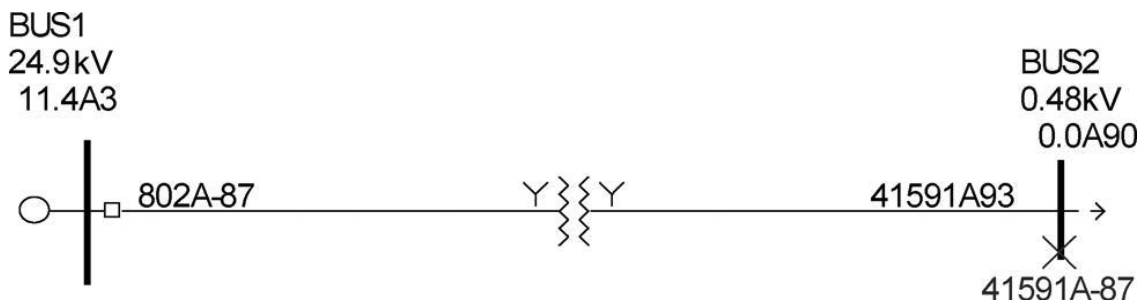

Fig. 6. Three-phase fault simulation. Phase A current shown.

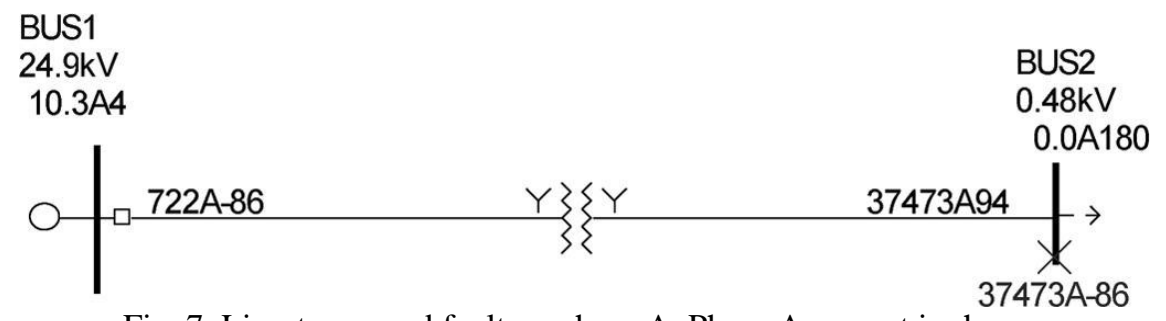

Fig. 7. Line-to-ground fault on phase A. Phase A current is shown

for maximum voltage sag. These results were obtained by running several simulations for each location. Simulations began with applying a 2-MW load, the equivalent of eight cars, and seeing how the system responded. If the simulation resulted in an undesirable voltage drop, the load was reduced by one car until an acceptable voltage drop was obtained.

2) Short-Circuit Study: Using the ASPEN software package, several short-circuit studies were performed at location "C." The results for a three-phase and a line-to-ground fault are shown in Figs. 6 and 7. The maximum current possible at a charging location is used to determine proper electrical protection. Locations " $\mathrm{A}$ " and "B," both at 24.9 $\mathrm{kV}$, were also simulated and had similar results as location "C."

3) Protection Study: To protect the 24.9-kV/480 V distribution transformer against short circuits and overcurrent, a properly sized fuse is required. Using the results of the short-circuit studies, a T65 fuse was chosen for the transformer under the expected maximum load current. Fig. 8 provides the coordination study for the chosen fuse curves, transformer damage, and inrush curves. As shown, this fuse will allow for transformer inrush current and provides overload protection. Note that due to the selection of a typical standard fuse, complete coordination with the transformer damage curve does not exist for arcing faults. Also, since the 13.2-kV system was not suit-able for a sudden 2-MW load, protection was not considered for $13.2-\mathrm{kV}$ cases.

4) Load Simulations: Computer simulations were performed to understand the effect of rapid recharge stations on the distribution system under various conditions. This section provides several simulations regarding the rapid charge station.

\section{CONCLUSION}

This paper presents the results of power-flow, short-circuit, protection, and transient studies for determining the effect of fast-charging stations at four actual locations within a utility company. The effect of a proposed rapid-charging station will be dependent on the utility system site. Locations that are associated with a strong source, such as B and C, do not require a compensation technique for the 2-MW load that may instantaneously come online due to the charging of up to eight EVs. Our results show that even with a dedicated transformer, at weaker locations, such as A and D, the number of cars that can be charged simultaneously may be limited. In this paper, it has been described the procedure for determining the limits for weak locations and summarized the results in Table II. In these cases, the rapid charge grid powered electric station for electric vehicle owner may be forced to apply a compensation. 


\section{International Advanced Research Journal in Science, Engineering and Technology}

Vol. 5, Issue 12, December 2018

\section{REFERENCES}

[1]. Tesla Motors Tech. Specs. 2008, Technical Specifications. [Online]. Available: http://www.teslamotors.com

[2]. Zenn Vehicles, Zenn Motor Co. Jun. 4, 2008. [Online]. Available: http://www.zenncars.com

[3]. Hybrid-Vehicles.net, "Toyota Prius", Hybrid Vehicles, Jun. 11, 2008. [Online]. Available: http://www.hybrid-vehicles.net/toyota-prius-hybrid.htm

[4]. Hybrid Cars, "Regenerative Braking", Regenerative Braking/Hybrid Cars, Jun. 11, 2008. [Online]. Available: http://www.hybridcars.com/ components/regenerative-braking.html

[5]. Phoenix Motorcars Inf. Specs. May 19, 2008, Electric Cars, Green Vehicles. [Online]. Available: http://www.phoenixmotorcars.com/pdf/ SUVSpecifications.pdf

[6]. I. Buchmann, Basics every battery user should know, 2005. [Online]. Available: http://www.batteryuniversity.com/partone.htm

[7]. M. H. Rashid, Power Electronics Handbook. San Diego, CA: Aca-demic Press, 2001, pp. 139-154, $183-196$.

[8]. A. M. Trzynadlowski, Introduction to Modern Power Electronics. New York: Wiley, 1998, pp. 123-195.

[9]. K. Heumann, Basic Principles of Power Electronics. Berlin, Ger-many: Springer-Verlag, 1986, pp. 13-35.

[10]. A. M. Rahimi, "Lithium-ion battery charger for charging up to eight cells," in Proc. Vehicle Power and Propulsion Conf., 2005, pp. 131-136.

[11]. J. Glover, M. Sarma, and T. Overbye, Power Systems: Analysis and Design, 4th ed. Toronto, ON, Canada: Thomas Learning, 2008, pp. 509512.

[12]. C. V. Walker, Electrical Distribution System Protection, 3rd ed. Pitts-burgh, PA: Cooper Power Systems, 1990, pp. $135-166$.

[13]. Distribution System Voltage Fluctuation Criteria. Reno, NV: NV En-ergy, 2007.

\section{BIOGRAPHY}

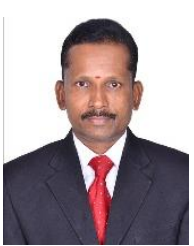

Dr. S. Devaneyan received the Ph.D. degree from Gandhigram Rural Institute - Central University, MHRD, Govt. of India and graduated from National Institute of Technology [NIT], Tiruchirappalli, Institute of National Importance, Govt. of India. Specialist in De-centralized Solar powered system design for various applications like Commercial, Industrial, Agricultural and Domestic. Also expert in Design and Development of Solar powered Electrical Vehicles for Passenger and Cargo applications. Received PhD Degree from Honourable Vice-President of India, His Excellency Shri. M. Venkaiah Naidu. Indigenously designed and developed various renewable energy products with innovations and applied patents more than 15 and published in IPJ [Indian Patent Journal]. Aiming for construction of self-sustainable India through rural entrepreneurs as per the guidance given by Former Honourable President of India, His Excellency Prof. Dr. A.P.J. Abdul Kalam. 